\title{
OCD symptoms in succinic semialdehyde dehydrogenase (SSADH) deficiency: a case report
}

Sachin Phakey ${ }^{1,2}$, Thomas Rego ${ }^{1,3}$, Frank Gaillard ${ }^{2,4}$, Julie Panetta ${ }^{5}$, Andrew Evans ${ }^{6}$, Gerard De Jong ${ }^{5}$ and Mark Walterfang ${ }^{1,3,7^{*}}$ (D)

\begin{abstract}
Background: Succinic semialdehyde dehydrogenase (SSADH) deficiency is a rare neurometabolic disorder resulting in a heterogeneous clinical phenotype. Adolescent and adult patients with SSADH deficiency may present with OCD symptoms. There is minimal literature regarding the pathological basis of OCD symptoms and their management amongst SSADH deficiency patients.

Case presentation: A 26-year-old woman with SSADH deficiency experienced obsessional slowness and hesitancy in her activities of daily living, with motor rituals and stereotypies of her hands and face. Neuroimaging revealed T2 hyperintensities of the globi pallidi bilaterally. Commencement of the serotonergic escitalopram moderately improved her OCD symptoms. The addition of the dopaminergic pramipexole hydrochloride yielded further improvement, following unsuccessful trial of other adjuncts: risperidone, methylphenidate and mirtazapine.

Conclusions: Pallidal pathology may explain the manifestation of OCD symptoms amongst individuals with SSADH deficiency. Serotonergic and concomitant dopaminergic therapy may be a viable treatment regimen for SSADH deficiency patients presenting with OCD symptoms.
\end{abstract}

Keywords: SSADH deficiency, Neuropsychiatry, Metabolic disorders, Obsessive-compulsive, Case report

\section{Background}

Succinic semialdehyde dehydrogenase (SSADH) deficiency (OMIM \#271980), also known as 4hydroxybutyric aciduria, is an autosomal recessive disorder in the degradation pathway of $\gamma$-aminobutyric acid (GABA): the central nervous system's predominant inhibitory neurotransmitter [1-3]. In SSADH deficiency, there is an accumulation of the compound $\gamma$ hydroxybutyric acid (GHB) (4-hydroxybutyric acid) within the cerebrospinal fluid, serum and urine [1, 4].

\footnotetext{
* Correspondence: mark.walterfang@mh.org.au

${ }^{1}$ Neuropsychiatry Unit, Royal Melbourne Hospital, Grattan St, Parkville, VIC 3050, Australia

${ }^{3}$ Department of Psychiatry, University of Melbourne, Parkville, VIC 3010, Australia

Full list of author information is available at the end of the article
}

Urinary organic acid analysis is used as a means of detecting GHB and diagnosing SSADH [5]. Neuroimaging is often useful as part of the diagnostic work-up. Magnetic resonance imaging (MRI) frequently reveals T2weighted hyperintensities involving the globi pallidi, subcortical white matter, cerebellar dentate nuclei and brainstem [5, 6]. A normal MRI may be observed in up to $43 \%$ of cases [6]. Confirmation of diagnosis may be achieved by genetic analysis of the ALDH5A1 gene encoding SSADH.

SSADH deficiency is rare, identified in approximately 450 patients worldwide [7]. SSADH deficiency has nonspecific symptomatology and a varied natural history throughout the life course [2, 5, 6, 8-10]. Hence, SSAD $\mathrm{H}$ deficiency is likely underdiagnosed $[7,9,10]$. In

C C The Author(s). 2020 Open Access This article is licensed under a Creative Commons Attribution 4.0 International License, which permits use, sharing, adaptation, distribution and reproduction in any medium or format, as long as you give appropriate credit to the original author(s) and the source, provide a link to the Creative Commons licence, and indicate if changes were made. The images or other third party material in this article are included in the article's Creative Commons licence, unless indicated otherwise in a credit line to the material. If material is not included in the article's Creative Commons licence and your intended use is not permitted by statutory regulation or exceeds the permitted use, you will need to obtain permission directly from the copyright holder. To view a copy of this licence, visit http://creativecommons.org/licenses/by/4.0/ The Creative Commons Public Domain Dedication waiver (http://creativecommons.org/publicdomain/zero/1.0/) applies to the data made available in this article, unless otherwise stated in a credit line to the data. 
infancy and childhood, individuals with SSADH deficiency typically present with global developmental delay, hypotonia, epilepsy and ataxia [5, 8, 9]. In addition to these clinical features, sleep disorders and neuropsychiatric symptoms are common manifestations in adolescence and adulthood $[6,7,9,10]$. Obsessive-compulsive disorder (OCD) symptoms have previously been observed in adolescents and adults [7, 9, 10]. Management of SSADH deficiency patients remains largely symptomatic $[7,11]$. Management of OCD symptoms in SSADH deficiency patients remains unclear and is generally guided by conventional guidelines for OCD treatment.

We describe the case of a 26-year-old woman with SSADH deficiency who developed obsessive-compulsive disorder (OCD)-like symptoms and our subsequent management approach. This case provides a possible framework for the management of future SSADH patients who present with similar symptoms.

\section{Case presentation}

Ms. A is a 26-year-old single unemployed woman referred to a tertiary Neuropsychiatry Unit for ongoing management of neuropsychiatric symptoms of SSADH deficiency. Delayed developmental milestones and seizures were noted from an early age. At 4 years of age, Ms. A was diagnosed with epilepsy and global developmental delay of unknown aetiology. No further work-up was conducted. She was treated with antiepileptic medication and early psychosocial intervention, attending specialised primary and secondary schools.

At 12 years of age, Ms. A was diagnosed with SSADH deficiency following the diagnosis of her younger brother with the same condition. Her diagnosis was confirmed via urinary organic acid quantification, with elevated 4hydroxybutyric acid and 4,5-dihydroxy hexanoic lactone levels. Genotyping was not performed. Formal neuropsychological testing at the time revealed mild-tomoderate intellectual disability.

From age 14, Ms. A experienced significant functional decline with manifestation of worsening OCD symptoms. She displayed marked difficulties initiating tasks, obsessional slowness and hesitancy in her activities of daily living, particularly when toileting and eating resulting in incontinence and weight loss, driven by obsessional doubt (about whether she was eating correctly or too quickly, had lifted her leg the correct way to put on trousers), and fears that certain behaviours may result in harm to her mother or brother. She exhibited motor rituals, particularly regarding the placement of food utensils and the correct "cutting" of food, and stereotypies of her hands and face involving wiping and chewing. Mealtimes were particularly problematic: prefaced by $30 \mathrm{~min}$ of pacing, 30-45 min of ordering cutlery, and then 1-2 $\mathrm{h}$ of slow mastication, marked by frequent pauses, requiring prompting to continue. She denied intrusive internal imagery. There were no religious or sexual preoccupations, counting or cleaning behaviours. Delusions and hallucinations were not apparent. Ms. A also showed increasing agitation and anxiety. When 22years-old, Ms. A was referred to the Neuropsychiatry Unit for assessment and symptomatic management of these symptoms. Her score on the Yale-Brown Obsessive-Compulsive Scale (Y-BOCS) at initial assessment was 33, denoting extreme OCD (0-13 mild, 14-25 moderate, 26-34 moderate-severe OCD; 35-40 severe OCD) [12]. On mental state, she was well-groomed and politely-engaged. She had markedly reduced eye contact and a mild fine tremor of her upper limbs. Her speech was slow, had low tone and was mildly dystonic. Her vocalisations were slow, with long latency and were brief. Her affect was restricted yet congruent with her mood. There were no psychotic phenomena, yet she was preoccupied with internal cognitions of doubt and uncertainty. Neurological examination revealed mildly elevated tone, particularly on augmentation, with cogwheeling and hyperreflexia bilaterally. She demonstrated occasional orobuccal lip-sucking movements and athetoid movements of the trunk. She had reduced arm swing when walking, pedestal turning, with reduced foot clearance and stride length. Eye movements showed some saccadic intrusions into slow pursuit movements, and saccadic over-and under-shoot requiring multiple small corrections. Her only treatment at this time was lamotrigine $75 \mathrm{mg}$ bd.

Neuroimaging revealed significant increased T2 signal in the pars interna and externa of the globi pallidi, substantiae nigrae and dentate nuclei bilaterally (Fig. 1). Moderate volume loss was also evident involving primarily the frontal lobe white matter, deep grey matter nuclei, brainstem and cerebellum.

Ms. A commenced the serotonergic medication escitalopram, which was gradually up-titrated from $10 \mathrm{mg}$ to 70 mg od. This moderately improved her obsessional slowness, psychomotor retardation and motor rituals. Spontaneity in initiating movements and complex activities remained problematic. Her Y-BOCS scale decreased to 24 over 18 months, and the duration of mealtimes halved.

Further attempts to optimise Ms. A's residual OCD symptoms were made: the adjuncts risperidone $0.5 \mathrm{mg}$ od, methylphenidate $5 \mathrm{mg}$ od, mirtazapine $7.5 \mathrm{mg}$ od were added cumulatively. These medications offered no benefit with her obsessive-compulsive phenomena. These were discontinued in turn due to worsening extrapyramidal side effects, agitation and social withdrawal, and hypersomnolence respectively. Conservative and non-pharmacologic therapies were also trialled to manage Ms. A's OCD symptoms to improve her obsessional slowness and break compulsive rituals. 


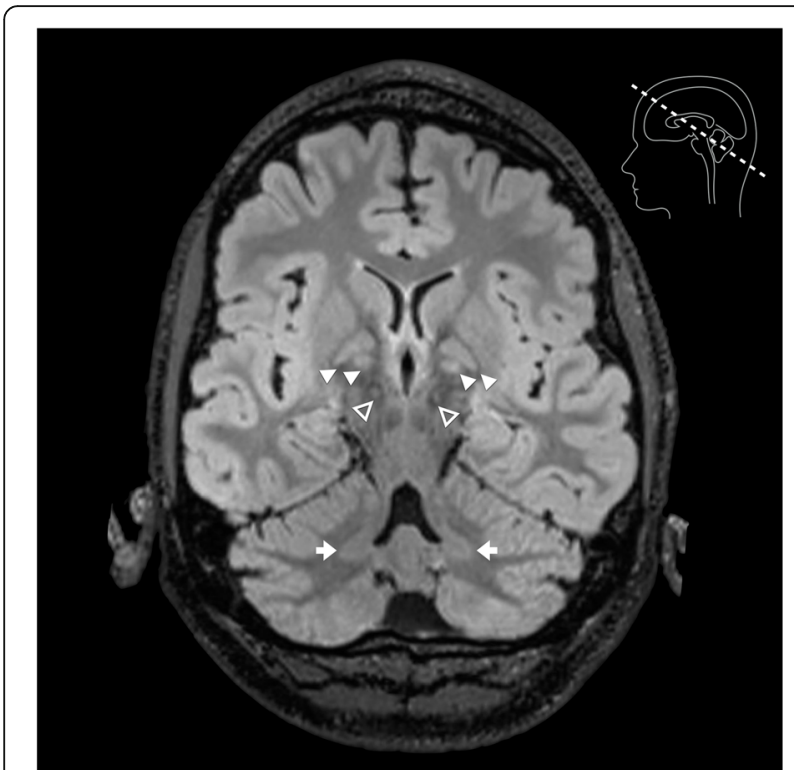

Fig. 1 Oblique axial FLAIR image demonstrating increased T2 signal in the pars interna and externa of the globi pallidi (solid arrow heads), substantiae nigrae (open arrow heads) and dentate nuclei (arrows)

At age 25, Ms. A's anxiety improved using lorazepam $1 \mathrm{mg}$ bd. Shortly thereafter Ms. A commenced the dopaminergic pramipexole hydrochloride, up-titrated from $0.25 \mathrm{mg}$ to $0.5 \mathrm{mg}$ bd. This significantly improved her obsessional slowness, motor initiation and psychomotor speed, with a reduction in mealtime duration by a further $50 \%$. Further attempts to increase the dose of pramipexole hydrochloride yielded increased initiation and volition, yet increased Ms. A's anxiety and agitation. She continued with pramipexole hydrochloride $0.5 \mathrm{mg}$ bd. Ms. A had significant functional improvement in undertaking her activities of daily living, increased social engagement and a markedly increased hedonic response.

\section{Discussion and conclusions}

OCD symptoms are a relatively common neuropsychiatric manifestation of SSADH deficiency in adolescents and adults. In their SSADH-deficient patient database $(n=33)$, Knerr et al. [9] found $11(33 \%)$ adolescents and adults displayed OCD symptoms. Similarly, 12 (48\%) adults presented with OCD behaviours in LapalmeRemis' et al. [10] analysis of their SSADH-deficient database $(n=25)$.

Bilateral changes to the globi pallidi have been described in SSADH deficiency, with macroscopic findings including well-circumscribed pallidal discolouration and hyperaemia [13]. These changes correspond with areas of increased T2 signal in the globi pallidi on neuroimaging [13], consistent with the findings reported in this patient. Pallidal pathology could be a possible explanation for this patient's presentation. The association between pallidal pathology and development of OCD and other compulsive disorders has been well-documented [1416], with disruption to the integrity of specific frontalsubcortical tracts including the lateral orbitofrontal loop [17] (Fig. 2). Excitatory glutamergic and inhibitory GABAergic cortical tracts from the orbitofrontal cortex and anterior cingulate cortex converge on the globus pallidus via the striatum $[18,19]$. Projections from the globus pallidus to the thalamus and then back to the cortex completes this neural circuit $[18,19]$. When pathology of the globus pallidus occurs, this results in an imbalance within these neural circuits [19]. This may thus underpin our patient's constellation of "inhibitory" symptoms (obsessional slowness and hesitancy) and "excitatory" symptoms (motor rituals, stereotypies and agitation). It is possible that the degree of pallidal pathology is associated with OCD symptom severity.

Despite the prevalence of OCD symptoms amongst SSADH deficiency patients, there is a gap in knowledge regarding the optimal management approach. Knerr et al. [9] describe one individual whose anxiety and OCD symptoms responded positively to fluoxetine 20 $\mathrm{mg} /$ day used concomitantly with methylphenidate 10 $20 \mathrm{mg}$ tds, risperidone $2 \mathrm{mg}$ bd and carbamazepine 20 $\mathrm{mg} / \mathrm{kg} /$ day. To our knowledge, there is no other literature detailing OCD symptom response to management.

Our case also suggests benefit in using a selective serotonin reuptake inhibitor: Ms. A had moderate

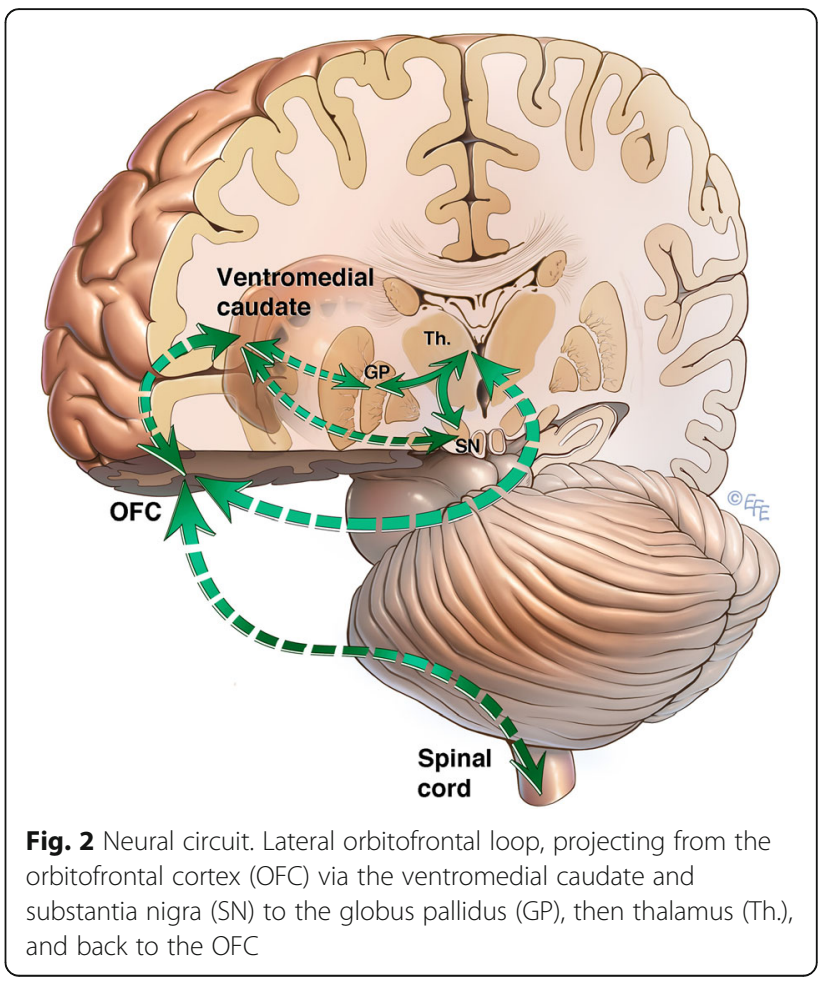


improvement in her OCD symptoms using escitalopram. Methylphenidate and risperidone provided no benefit. Use of the stimulant methylphenidate also worsened Ms. A's comorbid agitation and anxiety. In this regard, we hypothesised an anxiety-based obsessionality underpinned Ms. A's OCD symptoms.

The dopamine agonist pramipexole hydrochloride was added to address Ms. A's constellation of OCD and movement symptoms. This is the first report of the utility of this agent in SSADH deficiency. Increasing pramipexole hydrochloride dose increased Ms. A's motor initiation and psychomotor speed, however, at the cost of increased anxiety and agitation. This reaffirmed our hypothesis of an anxiety-grounding to Ms. A's obsessivecompulsive phenomena.

OCD symptoms are a possible neuropsychiatric manifestation in individuals with SSADH deficiency. Overall, our case suggests use of the serotonergic agent escitalopram in conjunction with dopaminergic pramipexole hydrochloride is a potentially effective symptomatic treatment regimen in patients with SSADH deficiency presenting with OCD symptoms. Dosage of pramipexole hydrochloride should be titrated according to patient symptoms and side effects. This is particularly important in SSADH-deficient individuals who present with OCD symptoms and anxiety, as their OCD symptoms may have an anxiety-basis. This ensures OCD symptom optimisation whilst preventing increasing agitation. Further studies into the management approach of OCD and other neuropsychiatric symptoms in SSADH deficiency patients are required. The management of this clinical case demonstrates a possible treatment algorithm for SSADH deficiency patients with OCD symptoms, suggesting that serotonergic treatment is the mainstay, but may be augmented by dopaminergic and other therapy to reduce slowness without worsening anxiety or agitation.

\section{Abbreviations}

SSADH: Succinic semialdehyde dehydrogenase; OCD: Obsessive-compulsive disorder; GABA: $\gamma$-aminobutyric acid; GHB: $\gamma$-hydroxybutyric acid;

MRI: Magnetic resonance imaging

\section{Acknowledgements}

The authors would like to acknowledge the Royal Melbourne Hospital Department of Neuropsychiatry and Department of Metabolic Medicine for their assistance, and Dr. Levent Efe for his illustrative work.

\section{Authors' contributions}

SP compiled the data and drafted the manuscript. TR and MW edited and critically revised the article, and obtained informed written consent from the patient's mother and legal guardian. FG provided imaging studies and edited the manuscript. JP, AE and GDJ discussed and critically revised the manuscript. All authors read and approved the final manuscript.

\section{Funding}

No funding was received to conduct this report.
Availability of data and materials

All data generated or analysed during this study are included in this published article.

Ethics approval and consent to participate

Not applicable.

\section{Consent for publication}

Informed written consent for the case report was provided by the patient's mother and legal guardian, who also reviewed the final draft of the manuscript.

\section{Competing interests}

The authors declare that they have no competing interests.

\section{Author details}

${ }^{1}$ Neuropsychiatry Unit, Royal Melbourne Hospital, Grattan St, Parkville, VIC 3050, Australia. ${ }^{2}$ Faculty of Medicine, Dentistry and Health Sciences at The University of Melbourne, Grattan St, Parkville, VIC 3010, Australia.

${ }^{3}$ Department of Psychiatry, University of Melbourne, Parkville, VIC 3010, Australia. ${ }^{4}$ Department of Radiology, Royal Melbourne Hospital, Grattan St, Parkville, VIC 3050, Australia. ${ }^{5}$ Metabolic Diseases Unit, Royal Melbourne Hospital, Grattan St, Parkville, VIC 3050, Australia. ${ }^{6}$ Department of Neurology, Royal Melbourne Hospital, Grattan St, Parkville, VIC 3050, Australia.

${ }^{7}$ Melbourne Neuropsychiatry Centre, University of Melbourne, Parkville, VIC 3010, Australia.

Received: 18 April 2020 Accepted: 21 July 2020

Published online: 05 August 2020

\section{References}

1. Jakobs C, Jaeken J, Gibson KM. Inherited disorders of GABA metabolism. J Inherit Metab Dis. 1993;16(4):704-15.

2. Gibson KM, Gupta M, Pearl PL, Tuchman M, Vezina LG, Snead OC, et al. Significant behavioral disturbances in succinic semialdehyde dehydrogenase (SSADH) deficiency (gamma-Hydroxybutyric aciduria). Biol Psychiatry. 2003; 54(7):763-8.

3. Pearl PL, Gibson KM, Cortez MA, Wu Y, Snead OC, Knerr l, et al. Succinic semialdehyde dehydrogenase deficiency: lessons from mice and men. J Inherit Metab Dis. 2009;32(3):343-52.

4. Gibson KM, Sweetman L, Nyhan WL, Jakobs C, Rating D, Siemes $H$, et al. Succinic semialdehyde dehydrogenase deficiency: an inborn error of gamma-aminobutyric acid metabolism. Clin Chim Acta. 1983;133(1):33-42.

5. Pearl PL, Gibson KM, Acosta MT, Vezina LG, Theodore WH, Rogawski MA et al. Clinical spectrum of succinic semialdehyde dehydrogenase deficiency. Neurology. 2003;60(9):1413-7.

6. Pearl PL, Capp PK, Novotny EJ, Gibson KM. Inherited disorders of neurotransmitters in children and adults. Clin Biochem. 2005:38(12):1051-8.

7. Pearl PL, Shukla L, Theodore WH, Jakobs C, Michael GK. Epilepsy in succinic semialdehyde dehydrogenase deficiency, a disorder of GABA metabolism. Brain and Development. 2011;33(9):796-805.

8. Gibson KM, Christensen E, Jakobs C, Fowler B, Clarke MA, Hammersen G, et al. The clinical phenotype of succinic semialdehyde dehydrogenase deficiency (4-hydroxybutyric aciduria): case reports of 23 new patients. Pediatrics. 1997:99(4):567-74

9. Knerr I, Gibson KM, Jakobs C, Pearl PL. Neuropsychiatric morbidity in adolescent and adult succinic semialdehyde dehydrogenase deficiency patients. CNS spectrums. 2008;13(7):598-605.

10. Lapalme-Remis S, Lewis EC, De Meulemeester C, Chakraborty P, Gibson KM, Torres $C$, et al. Natural history of succinic semialdehyde dehydrogenase deficiency through adulthood. Neurology. 2015;85(10):861-5.

11. Vogel KR, Pearl PL, Theodore WH, McCarter RC, Jakobs C, Gibson KM. Thirty years beyond discovery_clinical trials in succinic semialdehyde dehydrogenase deficiency, a disorder of GABA metabolism. J Inherit Metab Dis. 2012;36(3):401-10.

12. Storch EA, De Nadai AS, Conceicao do Rosario M, Shavitt RG, Torres AR, Ferrao YA, et al. Defining clinical severity in adults with obsessivecompulsive disorder. Compr Psychiatry. 2015;63:30-5.

13. Knerr I, Gibson KM, Murdoch G, Salomons GS, Jakobs C, Combs S, et al. Neuropathology in succinic semialdehyde dehydrogenase deficiency. Pediatr Neurol. 2010;42(4):255-8. 
14. Rodrigo Escalona P, Adair JC, Roberts BB, Graeber DA. Obsessive-compulsive disorder following bilateral globus pallidus infarction. Biol Psychiatry. 1997; 42(5):410-2.

15. Junqué $C$, Alegret $M$, Nobbe FA, Valldeoriola F, Pueyo $R$, Vendrell $P$, et al. Cognitive and behavioral changes after unilateral posteroventral pallidotomy: relationship with lesional data from MRI. Mov Disord. 1999; 14(5):780-9.

16. Ghika J, Ghika-Schmid F, Fankhauser H, Assal G, Vingerhoets F, Albanese A, et al. Bilateral contemporaneous posteroventral pallidotomy for the treatment of Parkinson's disease: neuropsychological and neurological side effects. Report of four cases and review of the literature. J Neurosurg. 1999; 91(2):313-21.

17. Walterfang M, Evans A, Looi JC, Jung HH, Danek A, Walker RH, et al. The neuropsychiatry of neuroacanthocytosis syndromes. Neurosci Biobehav Rev. 2011;35(5):1275-83.

18. Bonelli RM, Cummings JL. Frontal-subcortical circuitry and behavior. Dialogues Clin Neurosci. 2007;9(2):141-51.

19. Maia TV, Cooney RE, Peterson BS. The neural bases of obsessive-compulsive disorder in children and adults. Dev Psychopathol. 2008;20(4):1251-83.

\section{Publisher's Note}

Springer Nature remains neutral with regard to jurisdictional claims in published maps and institutional affiliations.

Ready to submit your research? Choose BMC and benefit from:

- fast, convenient online submission

- thorough peer review by experienced researchers in your field

- rapid publication on acceptance

- support for research data, including large and complex data types

- gold Open Access which fosters wider collaboration and increased citations

- maximum visibility for your research: over $100 \mathrm{M}$ website views per year

At $\mathrm{BMC}$, research is always in progress.

Learn more biomedcentral.com/submissions 